\title{
Study of Depression and Its Associated Factors among Women Living with HIV/AIDS in Coastal South India
}

\author{
B. Unnikrishnan, ${ }^{1}$ Vinita Jagannath, ${ }^{1}$ John T. Ramapuram, ${ }^{2}$ B. Achappa, ${ }^{2}$ and D. Madi \\ ${ }^{1}$ Department of Community Medicine, Kasturba Medical College, Manipal University, Light House Hill Road, \\ Mangalore 575001, India \\ ${ }^{2}$ Department of Medicine, Kasturba Medical College, Manipal University, Light House Hill Road, Mangalore 575001, India
}

Correspondence should be addressed to Vinita Jagannath, vjp.1988@gmail.com

Received 1 March 2012; Accepted 29 April 2012

Academic Editors: R. L. D. Machado, M. Patel, and J. Poudrier

Copyright ( $) 2012$ B. Unnikrishnan et al. This is an open access article distributed under the Creative Commons Attribution License, which permits unrestricted use, distribution, and reproduction in any medium, provided the original work is properly cited.

\begin{abstract}
Background. Depression is one of the most prevalent psychiatric diagnoses seen in HIV-positive individuals. Women with HIV are about four times more likely to be depressed than those who are not infected. Aims. To assess the sociodemographic and clinical correlates of depression among women living with HIV/AIDS. Setting and Design. One public and one private hospital in Mangalore, Coastal South India, and cross-sectional design. Methods and Materials. Study constituted of 137 HIV-positive women, depression was assessed using BDI (Beck Depression Inventory), and social support was assessed using Lubben Social Network Scale. Statistical Analysis. All analysis was conducted using SPSS version 11.5. Chi-square test with $P$ value less than 0.05 was taken as statistically significant. Results. Among $137 \mathrm{HIV}$-positive women, $51.1 \%$ were depressed. Around $16 \%$ were having moderate to high risk for isolation. Depression was statistically significant in rural women, widowed women, and lower socioeconomic class women. Conclusion. Depression is highly prevalent among women living with HIV which is still underdiagnosed and undertreated, and there is a need to incorporate mental health services as an integral component of HIV care.
\end{abstract}

\section{Introduction}

The acquired immuno deficiency syndrome (AIDS) is the most dreadful epidemic that mankind has ever witnessed. Depression is a common psychiatric illness characterized by low mood, decreased interest, and anergia along with a plethora of other vegetative and cognitive symptoms. Depression is a frequent consequence of trying to cope with chronic illness. Depressive symptoms in HIV positive women are associated with impaired adherence to antiretroviral therapy (ART), higher HIV plasma viral loads, higher mortality, less social support, and a worse quality of life. In resource poor setting, the burden of depression among HIV-positive people is more [1]. Major depressive disorder is four times higher in HIV-positive women (19.4\%) than in HIV-negative women (4.8\%) [2]. Women acquiring HIV infection is on rise these days. According to UNAIDS 2009 HIV estimates, women more than 15 years of age living with HIV in India are 730,000-1,000,000 and number of people living with HIV in India are 2,100,000-2,800,00
[3]. In India, married women are not considered as highrisk group for contracting or transmitting HIV as sexual relationships are considered to be monogamous in marriage. However, many studies suggest that married women are at risk of acquiring HIV [4-6]. HIV positive women face violent domestic attacks, financial constraints, rejection by family, spouses and community, compromised health care seeking, child care problems, emotional and mental health problems $[7,8]$. Lack of social support from the community and health care staff has generated anxiety and fear among HIV-positive women, ultimately leading to depression. Depression impairs immune function thereby altering the course of HIV infection [9]. It is seen that social support is inversely related to depression [10].

In this study, we have made an attempt to assess the sociodemographic and clinical correlates of depression among HIV-positive women. This in turn would help in designing programmes for prevention and treatment of HIVpositive women. 


\section{Materials and Methods}

2.1. Study Design. This was a cross-sectional study involving HIV-positive women between the age group of 20 to 60 years who were undergoing treatment at a tertiary level teaching private hospital (Kasturba Medical College, Attavar, Mangalore) and a public hospital in Mangalore, Coastal South India.

2.2. Sample and Setting. The sample size was calculated based on expected proportion of depression among HIVpositive women based on previous studies as 60\%, taking relative precision as $15 \%$ and confidence interval of $95 \%$, adding 20\% as nonresponse error, the sample size was found to be $137 \mathrm{HIV}$-positive women. HIV-positive women who came to the hospital for treatment, by order of arrival, were invited to participate in the interview. It was clarified to them that this procedure would not affect their scheduled consultations.

The procedure was clearly explained to them in their local language, and all aspects of confidentiality were reassured. Those who gave written informed consent participated in the study. The interviews were conducted in a separate medical consultation room and were performed by the main researcher along with infectious disease specialist; interview lasted for about 30 minutes. In the case of a patient feeling tired or uncomfortable, she was allowed to take a break following which she could resume. Women who were found to be depressed were referred to psychiatrist for further management. The study was approved by Institutional Ethics Committee.

A pretested semistructured questionnaire was used to collect the data. Socioeconomic status was assessed using modified Kuppuswamy scale [11] which has three parameters, namely, income, occupation and educational status. The socioeconomic classes of upper, upper middle and lower middle were grouped as middle class and upper lower and lower as lower class.

BDI-Beck Depression Inventory was used to know the severity of depression, and Lubben Social Network Scale was used to assess social support. All HIV-positive women diagnosed with depression were referred to the psychiatrist's clinic later, and appropriate treatment was provided individually.

BDI-Beck Depression Inventory [12]. The Beck Depression Inventory (BDI) is a series of questions developed to measure the intensity, severity, and depth of depression in patients with psychiatric diagnoses. Its long form is composed of 21 questions, each designed to assess a specific symptom common among people with depression (see Table 1).

Lubben Social Network Scale [13]. It is a self-report 10items scale to assess the level of social support available to a person. Each item is rated from 0 to 5. It has five domains including family network, friends' network and confidant relationship, helping others, and living arrangements. The
TABLe 1

\begin{tabular}{lc}
\hline Score & Severity of depression \\
\hline $0-9$ & Normal \\
$10-16$ & Mild depression \\
$17-29$ & Moderate depression \\
$30-63$ & Severe depression \\
\hline
\end{tabular}

TABLE 2

\begin{tabular}{lc}
\hline Score & Risk of isolation \\
\hline$<20$ & Isolated \\
$21-25$ & High risk for isolation \\
$26-30$ & Moderate risk for isolation \\
$\geq 31$ & Low risk for isolation \\
\hline
\end{tabular}

minimum score is 0 and maximum is 50 , higher scores indicating greater level of social support (see Table 2).

2.3. Statistical Analysis. All analysis was conducted using SPSS (Statistical Package for Social Sciences) version 11.5. Chi-square test with $P$ value less than 0.05 was taken as statistically significant.

\section{Results}

As seen in Table 3, this study included 137 subjects. Out of this, $72(52.6 \%)$ were from rural area and 65 (47.4\%) were from urban area. Rural women were more depressed than urban women, and it was statistically significant. Majority of the subjects $(83.2 \%)$ were middle aged, that is, $30-50$ years which is productive population. $60.6 \%$ women were married, $23.4 \%$ were widowed, and $16 \%$ were single. It was found that widowed women were more depressed than married and single women, and it was statistically significant. Hindus constituted $80.3 \%$ followed by Christians (14.6\%) and Muslims (5.1\%). Around 35\% belonged to middle class $65 \%$ belonged to lower class, lower class women were more depressed than upper class women, and it was found to be statistically significant. Majority of the women $(80.3 \%)$ acquired the infection through sexual route, $13.9 \%$ acquired through blood, and remaining (5.8\%) acquired by other routes of transmission. Women on ART constituted $36.5 \%$, and $63.5 \%$ were not on ART. Women with CD4 count more than 250 were $64.2 \%$, and CD4 count less than 250 were $35.8 \%$.

Table 4 shows $51.1 \%$ were depressed and $48.9 \%$ were not depressed. $16 \%$ of the women had moderate to high risk for isolation, and $84 \%$ of the women had low risk for isolation.

As shown in Table 5, 41.6\% women who had low risk for isolation were depressed, $9.5 \%$ women who had moderate to high risk for isolation were depressed. There was no statistically significant association between depression and social support. 
TABLE 3: Baseline characteristics of study population $(n=137)$.

\begin{tabular}{|c|c|c|c|}
\hline \multirow{2}{*}{ Characteristics } & \multicolumn{2}{|c|}{ BDI score } & \multirow[b]{2}{*}{$P$ value* } \\
\hline & $\begin{array}{c}\text { Not } \\
\text { depressed } \\
N(\%)\end{array}$ & $\begin{array}{c}\text { Depressed } \\
N(\%)\end{array}$ & \\
\hline \multicolumn{4}{|l|}{ Residence } \\
\hline Urban & $43(66.2 \%)$ & $22(33.8 \%)$ & \multirow{2}{*}{$<0.001$} \\
\hline Rural & $24(33.3 \%)$ & $48(66.7 \%)$ & \\
\hline \multicolumn{4}{|l|}{ Marital status } \\
\hline Single & $15(68.2 \%)$ & $7(31.8 \%)$ & \multirow{3}{*}{$<0.001$} \\
\hline Married & $46(55.4 \%)$ & $37(44.6 \%)$ & \\
\hline Widowed & $6(18.8 \%)$ & $26(81.3 \%)$ & \\
\hline \multicolumn{4}{|l|}{ Religion } \\
\hline Hindu & $52(47.3 \%)$ & $58(52.7 \%)$ & \multirow{3}{*}{0.54} \\
\hline Muslim & $3(42.9 \%)$ & $4(57.1 \%)$ & \\
\hline Christian & $12(60 \%)$ & $8(40 \%)$ & \\
\hline \multicolumn{4}{|c|}{ Mode of transmission } \\
\hline Sexual & $55(50 \%)$ & $55(50 \%)$ & \multirow{3}{*}{0.417} \\
\hline Blood & $7(36.8 \%)$ & $12(63.2 \%)$ & \\
\hline Other & $5(62.5 \%)$ & $3(37.5 \%)$ & \\
\hline \multicolumn{4}{|c|}{ Time since diagnosis } \\
\hline$<5$ years & $39(43.8 \%)$ & $50(56.2 \%)$ & \multirow{2}{*}{0.075} \\
\hline$>5$ years & $28(58.3 \%)$ & $20(41.7 \%)$ & \\
\hline \multicolumn{4}{|c|}{ Antiretroviral treatment (Art) } \\
\hline On art & $25(50 \%)$ & $25(50 \%)$ & \multirow{2}{*}{0.493} \\
\hline Not on art & $42(48.3 \%)$ & $45(51.7 \%)$ & \\
\hline \multicolumn{4}{|c|}{ Socioeconomic status (Ses) } \\
\hline Middle Ses & $36(75 \%)$ & $12(25 \%)$ & \multirow{2}{*}{$<0.001$} \\
\hline Lower Ses & $31(34.8 \%)$ & $58(65.2 \%)$ & \\
\hline \multicolumn{4}{|l|}{ CD4 group } \\
\hline$<250$ & $27(55.1 \%)$ & $27(44.9 \%)$ & \multirow{2}{*}{0.183} \\
\hline$>250$ & $40(45.5 \%)$ & $48(54.5 \%)$ & \\
\hline
\end{tabular}

${ }^{*} P$ value less than 0.05 taken as statistically significant.

TABLE 4: Assessment of depression and social support.

\begin{tabular}{lcc}
\hline Parameters & $N$ & $\%$ \\
\hline Depression & & \\
$\quad$ Not depressed $\left({ }^{*}\right.$ BDI score $\left.0-9\right)$ & 67 & $48.9 \%$ \\
$\quad$ Depressed (*BDI score $10-63)$ & 70 & $51.1 \%$ \\
Social support & & \\
$\quad$ High risk for isolation $\left({ }^{*}\right.$ LSNS score $\left.21-25\right)$ & 15 & $10.9 \%$ \\
$\quad$ Moderate risk for isolation $\left({ }^{*}\right.$ LSNS score $\left.26-30\right)$ & 7 & $5.1 \%$ \\
Low risk for isolation $\left({ }^{*}\right.$ LSNS score $\left.\geq 31\right)$ & 115 & $84 \%$ \\
\hline
\end{tabular}

${ }^{*}$ BDI: Beck Depression Inventory.

"LSNS: Lubben Social Network Scale.

\section{Discussion}

In this study, 137 HIV-positive women were studied as shown in Table 3. As seen in Table 3, a statistical significant association was found between depression and residence, that is, rural women were found to be more depressed than urban women. This is because rural women are isolated
TABLE 5: Comparison of depression and social support.

\begin{tabular}{lccc}
\hline Parameters & \multicolumn{2}{c}{ Depression } & Not \\
& $\begin{array}{c}\text { Depressed } N \\
(\%)\end{array}$ & $\begin{array}{c}\text { Depressed } \\
N(\%)\end{array}$ & \\
& & & \\
\hline Social support & & & \\
High risk for isolation & $6(40 \%)$ & $9(60 \%)$ & \\
Moderate risk for isolation & $3(42.9 \%)$ & $4(57.1 \%)$ & 0.71 \\
Low risk for isolation & $58(50.4 \%)$ & $57(49.6 \%)$ & \\
${ }^{*} P$ value less than 0.05 taken as statistically significant.
\end{tabular}

from social services and health care services because of lack of transportation and conservative society in rural areas which forces them not to disclose their HIV status thus depriving them of the social support and ultimately leading to depression [14]. Lower class women and widowed women were found to be more depressed than middle class women and married and single women, respectively, and it was found to be statistically significant. Financial burden and illiteracy make lower socioeconomic status more prone for depression [15]. Widow/widower does not get support from their family and are worried about the future of their kids and are more prone for depression. In a study, widows were at high risk for depression [16]. A study showed that marriage provides a social support system, and married people are less prone for depression [17]. Majority of the women $(80.3 \%)$ acquired the infection through sexual route, $13.9 \%$ acquired through blood and remaining (5.8\%) acquired by other routes of transmission. In our country, professional blood donation is banned since January 1 1998. Since then blood donation is voluntary. Blood is procured from NACO (National AIDS Control Organization) accredited blood banks where blood is screened for five diseases, namely HIV, hepatitis B, hepatitis C, syphilis and malaria. These are the steps taken by NACO to reduce transfusion transmitted infections [18].

As seen in Table 4, depression as assessed by Beck Depression Inventory (BDI) was found to be $51.1 \%$. Many studies have shown higher rates of depression among HIVpositive women than HIV-negative women $[19,20]$. 16\% of the women had moderate to high risk for isolation as social support assessed by Lubben Social Network Scale. A study showed that social support plays an important role in women's health [21].

As shown in Table 5, it was found that there was no statistically significant association between depression and social support. In Indian setting, women get very good social support because of closely knit family system and spouse support, this may be the reason for not finding association between social support and depression. On the contrary, many studies show that social support has protective influence on depression [22-24].

\section{Conclusion}

The present cross-sectional study is an attempt to elicit information among HIV-positive women. Depression in 
HIV-women was found to be $51.1 \%$. Depression was statistically significant in rural women, widowed women, and lower socioeconomic class women. Thus, depression is highly prevalent among women living with HIV which is still underdiagnosed and undertreated, and there is a need to incorporate mental health services as an integral component of HIV care.

\section{Limitations of the Study}

The following limitations apply to the findings of this study. As this was a cross-sectional studys we could not determine causal links between depression and social support. Other limitations are convenience sample and self-report measures.

\section{Conflict of Interests}

The authors declare that they have no competing interests.

\section{Acknowledgment}

The authors acknowledge the study subjects.

\section{References}

[1] P. Y. Collins, A. R. Holman, M. C. Freeman, and V. Patel, "What is the relevance of mental health to HIV/AIDS care and treatment programs in developing countries? A systematic review," AIDS, vol. 20, no. 12, pp. 1571-1582, 2006.

[2] M. F. Morrison, J. M. Petitto, T. Ten Have et al., "Depressive and anxiety disorders in women with HIV infection," The American Journal of Psychiatry, vol. 159, no. 5, pp. 789-796, 2002.

[3] UN AIDS, Epidemiological Fact Sheet on HIV and AIDS, Core Data on Epidemiology and Response, Press Release, 2009.

[4] R. R. Gangakhedkar, M. E. Bentley, A. D. Divekar et al., "Spread HIV infection in married monogamous women in India," Journal of the American Medical Association, vol. 278, no. 23, pp. 2090-2092, 1997.

[5] R. Kumar, P. Jha, P. Arora et al., "Trends in HIV-1 in young adults in south India from 2000 to 2004: a prevalence study," The Lancet, vol. 367, no. 9517, pp. 1164-1172, 2006.

[6] S. H. Mehta, A. Gupta, S. Sahay et al., "High HIV prevalence among a high-risk subgroup of women attending sexually transmitted infection clinics in Pune, India," Journal of Acquired Immune Deficiency Syndromes, vol. 41, no. 1, pp. 75$80,2006$.

[7] E. B. Joseph and R. S. Bhatti, "Psychosocial problems and coping patterns of HIV seropositive wives of men with HIV/AIDS," Social Work in Health Care, vol. 39, no. 1-2, pp. 29-47, 2004.

[8] B. E. Thomas, F. Rehman, D. Suryanarayanan et al., "How stigmatizing is Stigma in the life of people living with HIV: a study on HIV positive individuals from Chennai, South India," AIDS Care, vol. 17, no. 7, pp. 795-801, 2005.

[9] S. R. Penzak, Y. S. Reddy, and S. R. Grimsley, "Depression in patients with HIV infection," American Journal of HealthSystem Pharmacy, vol. 57, no. 4, pp. 376-389, 2000.

[10] T. L. McDowell and J. M. Serovich, "The effect of perceived and actual social support on the mental health of HIV-positive persons," AIDS Care, vol. 19, no. 10, pp. 1223-1229, 2007.
[11] N. Kumar, C. Shekhar, P. Kumar, and A. S. Kundu, "Kuppuswamy's socioeconomic status scale-updating for 2007," Indian Journal of Pediatrics, vol. 74, no. 12, pp. 1131-1132, 2007.

[12] A. T. Beck, R. A. Steer, and M. G. Garbin, "Psychometric properties of the Beck Depression Inventory: twenty-five years of evaluation," Clinical Psychology Review, vol. 8, no. 1, pp. 77100, 1988.

[13] J. Lubben and M. Gironda, "Measuring social networks and assessing their benefits," in Social Networks and Social Exclusion: Sociological and Policy Perspectives, C. Phillipson, G. Allan, and D. Morgan, Eds., 2004.

[14] M. Vyavaharkar, L. Moneyham, C. Murdaugh, and A. Tavakoli, "Factors associated with quality of life among rural women with HIV disease," AIDS and Behavior, vol. 16, no. 2, pp. 295-303, 2012.

[15] J. L. Wang, N. Schmitz, and C. S. Dewa, "Socioeconomic status and the risk of major depression: the Canadian national population health survey," Journal of Epidemiology and Community Health, vol. 64, no. 5, pp. 447-452, 2010.

[16] K. B. Carnelley, C. B. Wortman, and R. C. Kessler, "The impact of widowhood on depression: findings from a prospective survey," Psychological Medicine, vol. 29, no. 5, pp. 1111-1123, 1999.

[17] M. M. Weissman, R. C. Bland, G. J. Canino et al., "Crossnational epidemiology of major depression and bipolar disorder," Journal of the American Medical Association, vol. 276, no. 4, pp. 293-299, 1996.

[18] Voluntary Blood Donation Programme-An Operational Guideline, http://www.nacoonline.org/upload/Policies\%20\& \%20Guidelines/29,\%20voluntary\%20blood\%20donation .pdf.

[19] L. Moneyham, R. Sowell, B. Seals, and A. Demi, "Depressive symptoms among African American women with HIV disease.," Scholarly Inquiry for Nursing Practice, vol. 14, no. 1, pp. 9-39, 2000, discussion 41-46.

[20] J. A. Ciesla and J. E. Roberts, "Meta-analysis of the relationship between HIV infection and risk for depressive disorders," The American Journal of Psychiatry, vol. 158, no. 5, pp. 725-730, 2001.

[21] D. E. Hurdle, "Social support: a critical factor in women's health and health promotion," Health and Social Work, vol. 26, no. 2, pp. 72-79, 2001.

[22] P. S. Chandra, V. Ravi, A. Desai, and D. K. Subbakrishna, "Anxiety and depression among HIV-infected heterosexualsa report from India," Journal of Psychosomatic Research, vol. 45, no. 5, pp. 401-409, 1998.

[23] H. Klein, K. W. Elifson, and C. E. Sterk, "Depression and HIV risk behavior practices among "At Risk" women," Women and Health, vol. 48, no. 2, pp. 167-188, 2008.

[24] J. M. Simoni, B. Huang, E. J. Goodry, and H. D. Montoya, "Social support and depressive symptomatology among HIVpositive women: the mediating role of self-esteem and mastery," Women and Health, vol. 42, no. 4, pp. 1-15, 2006. 


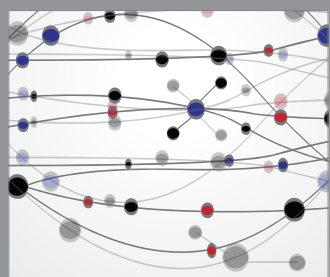

The Scientific World Journal
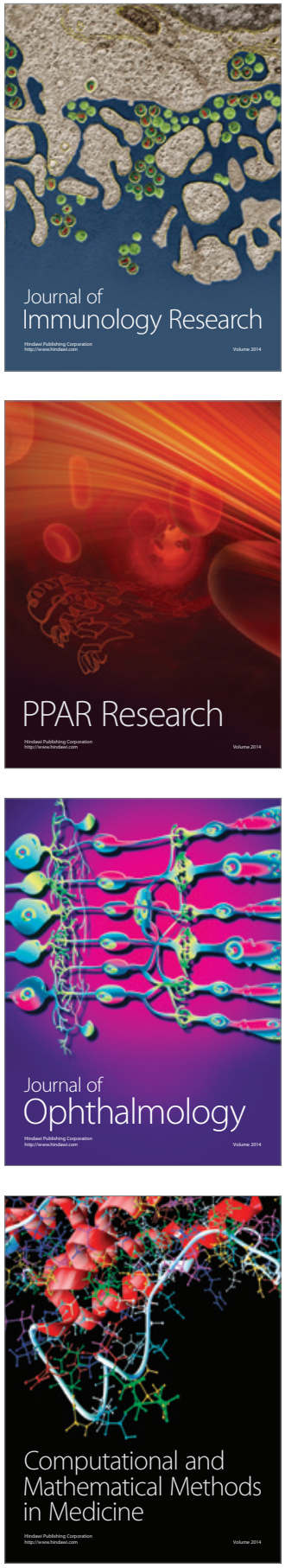

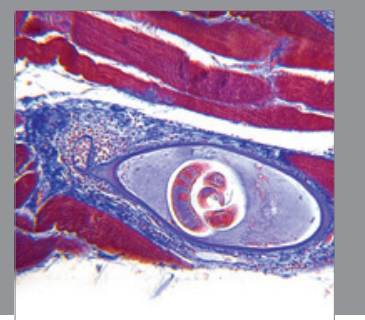

Gastroenterology

Research and Practice
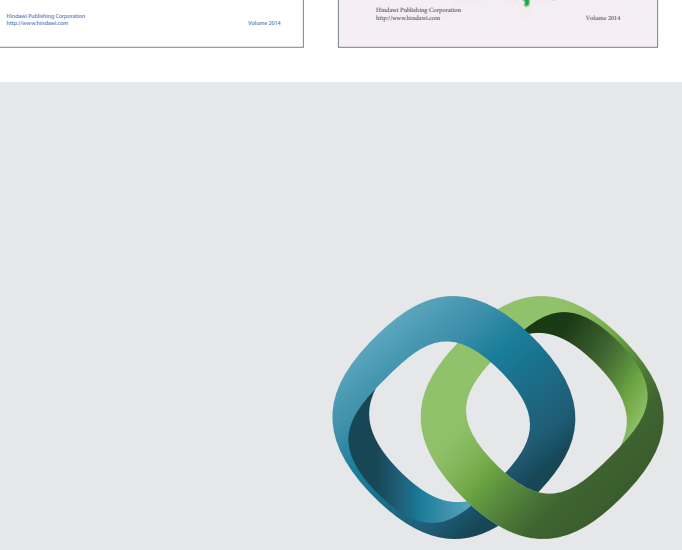

\section{Hindawi}

Submit your manuscripts at

http://www.hindawi.com
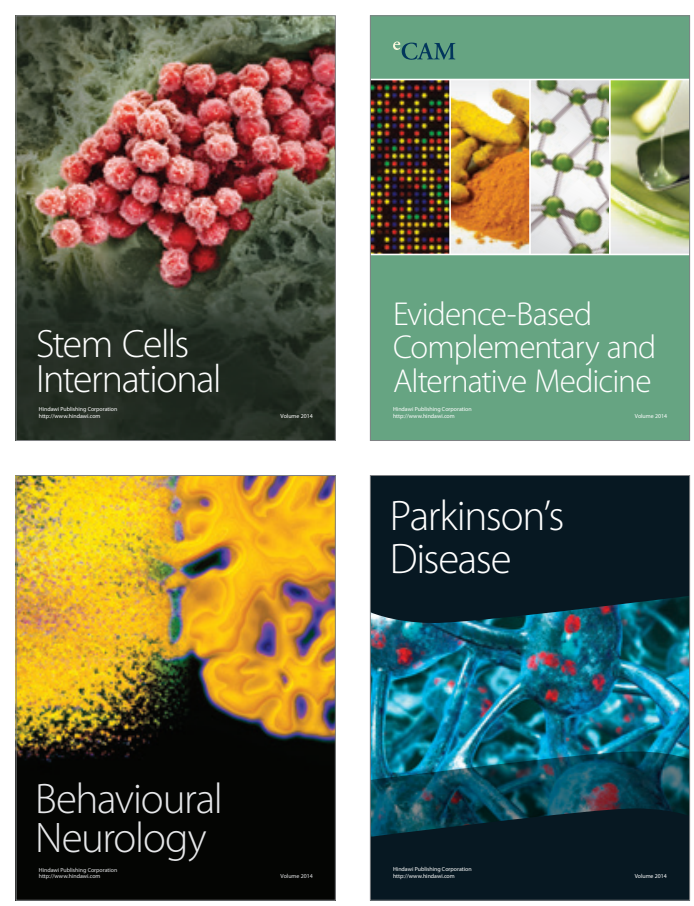

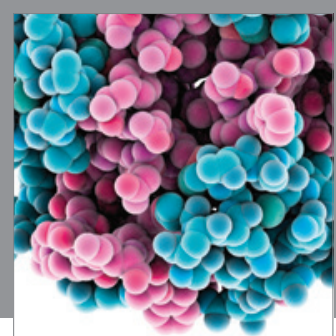

Journal of
Diabetes Research

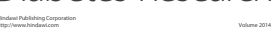

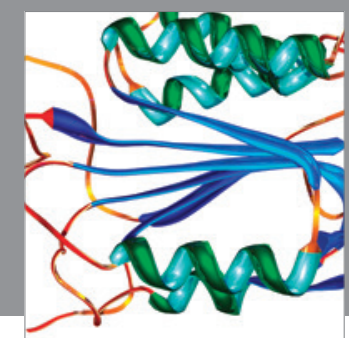

Disease Markers
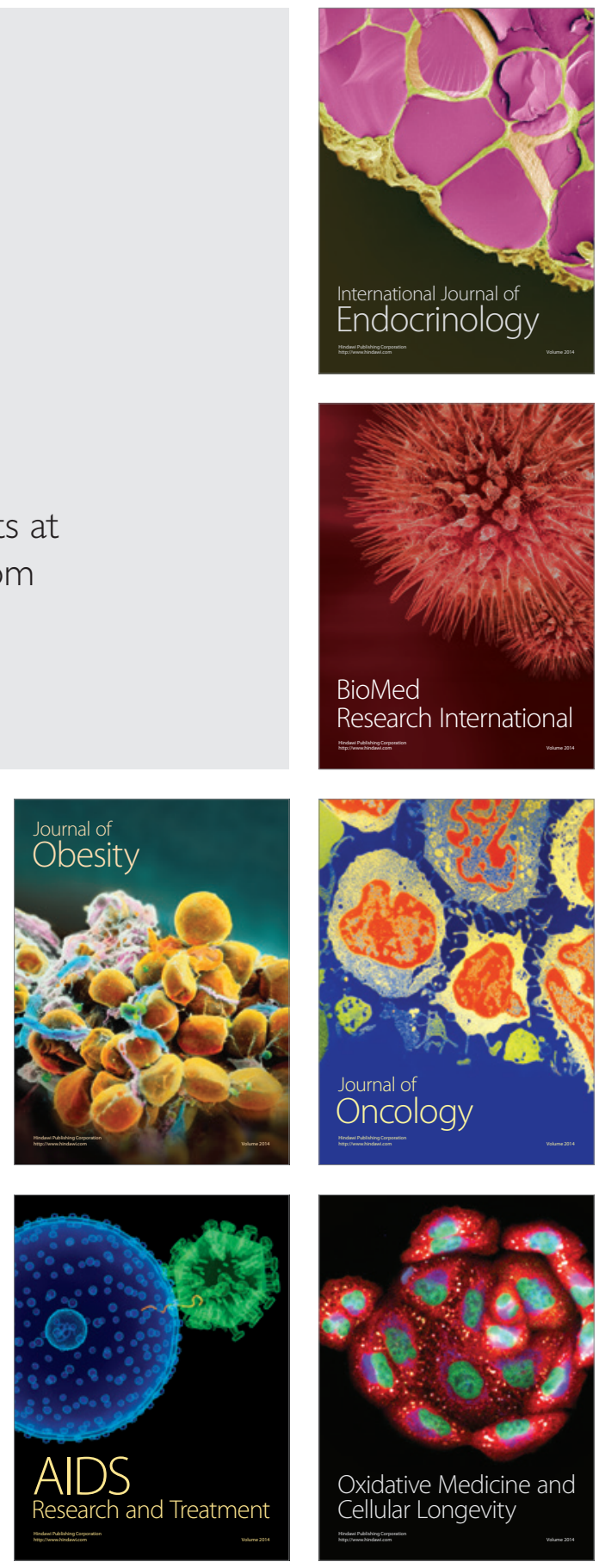